\title{
The influence of grinding speed on the creep-feed grinding process
}

Łukasz ŻYŁKA, Marcin PŁODZIEŃ, Robert BABIARZ

DOI: 10.30464/jmee.2018.2.4. 285

Cite this article as:

Żyłka Ł., Płodzień M., Babiarz R. The influence of grinding speed on the creep-feed grinding process. Journal of Mechanical and Energy Engineering, Vol. 2(42), No. 4, 2018, pp. 285-290.

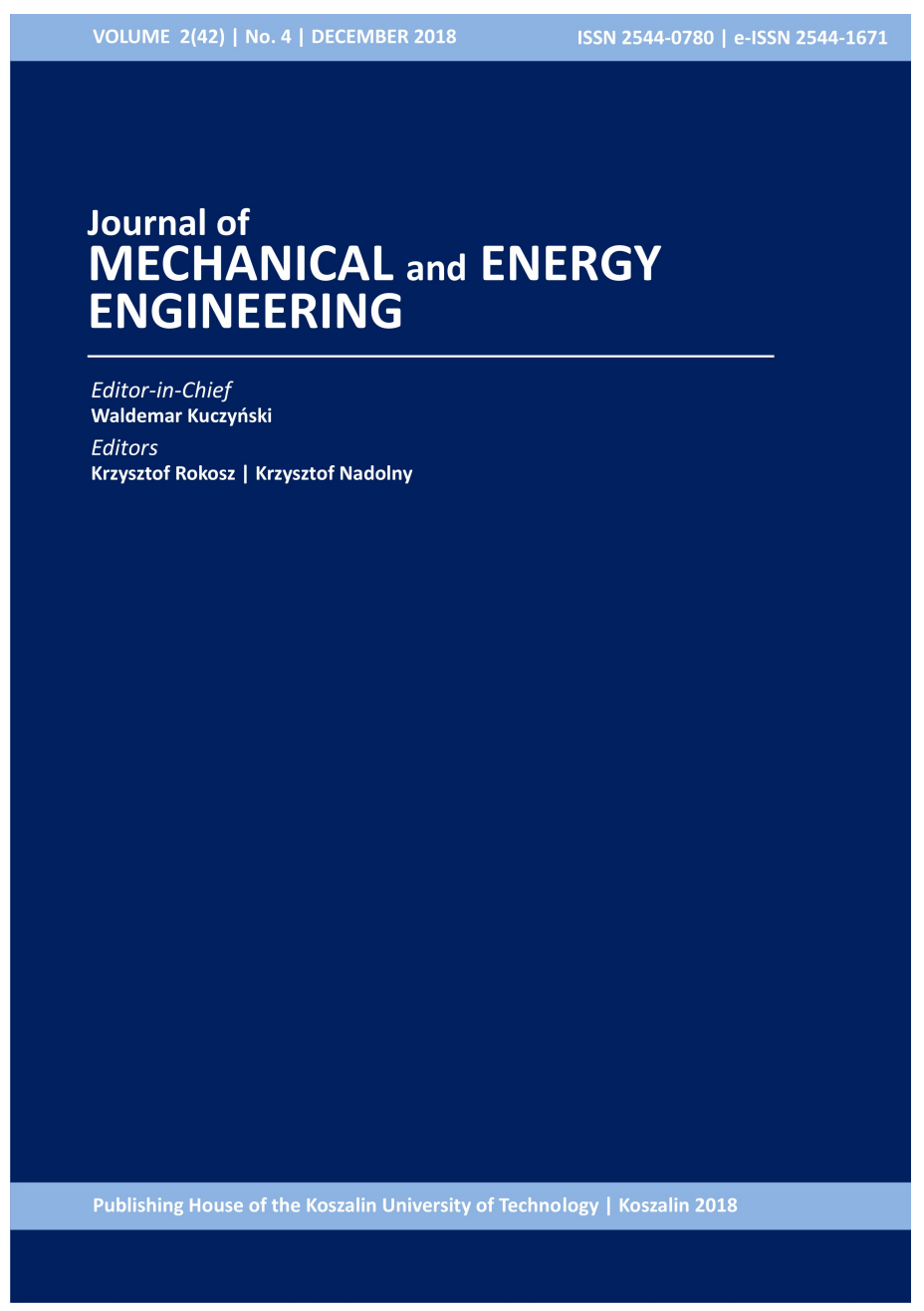

Journal of Mechanical and Energy Engineering

Website: jmee.tu.koszalin.pl

ISSN (Print): 2544-0780

ISSN (Online): 2544-1671

Volume: 2(42)

Number: 4

Year: 2018

Pages: 285-290

Article Info:

Received 5 December 2018

Accepted 19 December 2018

\section{Open Access}

This article is distributed under the terms of the Creative Commons Attribution 4.0 (CC BY 4.0) International License (http://creativecommons.org/licenses/by/4.0/), which permits unrestricted use, distribution, and reproduction in any medium, provided you give appropriate credit to the original author(s) and the source, provide a link to the Creative Commons license, and indicate if changes were made. 


\title{
THE INFLUENCE OF GRINDING SPEED ON THE CREEP-FEED GRINDING PROCESS
}

\author{
Łukasz ŻYŁKA ${ }^{1 *}$, Marcin PŁODZIEŃ² ${ }^{2}$, Robert BABIARZ ${ }^{3}$ \\ ${ }^{1 *}$ Rzeszow University of Technology, The Faculty of Mechanical Engineering and Aeronautics, Department \\ of Manufacturing Techniques and Automation, zylka@prz.edu.pl \\ ${ }^{2}$ Rzeszow University of Technology, The Faculty of Mechanical Engineering and Aeronautics, Department of \\ Manufacturing Techniques and Automation, \\ ${ }^{3}$ Rzeszow University of Technology, The Faculty of Mechanical Engineering and Aeronautics, Department of \\ Manufacturing Techniques and Automation,
}

(Received 5 December 2018, Accepted 19 December 2018)

\begin{abstract}
Grinding is usually the last stage of the technological process and determines the quality of manufactured products. One of the varieties of grinding more and more often used in practice is deep grinding which is called Creep-Feed Grinding. It is characterized by a high value of grinding infeed and slow feed. Technological parameters such as the depth of grinding and the speed of feed have a significant impact on the quality of the workpiece. However, also the grinding speed has an influence on the grinding process and the result of machining. Therefore, experimental studies on the impact of grinding speed on the surface roughness and grinding force components were carried out. The tests were realized in the deep-grinding grinding process of Inconel 718 with a grinding wheel made of mixture of sintered alumina and ruby corundum.
\end{abstract}

Keywords: grinding, creep-feed grinding, surface quality, grinding speed

\section{INTRODUCTION}

Materials which are often used in the aerospace industry are nickel based alloys, especially Inconel 718 alloy. The chemical composition of this alloy as well as physical and mechanical properties have negative influence on its machinability and grinding process [7]. Very often turning, milling or broaching Inconel alloys is too expensive and time-consuming, that's why these machining methods are usually replaced by grinding. Due to the very poor machinability of the Inconel 718 alloy, the most common type of grinding is deep grinding with a creeping feed which is called Creep-Feed Grinding (CFG) $[4,5]$.

CFG grinding is characterized by large depth of cut which reaches even $5 \div 20$ millimeters (fig. 1 ). It provides large scale metal removal similar to milling process [13]. The use of the large depth of cut causes necessity of grinding with very low workpiece speed which is called creep feed. However, Creep Feed Grinding process provides high productivity and great production efficiency [1]. Another advantage of CFG grinding is possibility of machining difficult and costly to shape materials like hardened steels, titanium alloys, nickel based alloys or ceramics. Specific characteristic of grinding wheels used in this process allows easy modification of their form [12].

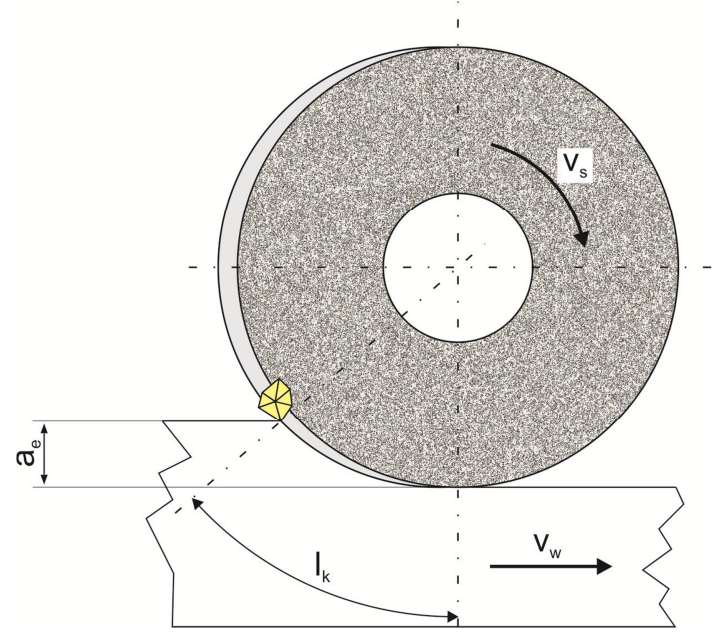

Fig. 1. Parameters of Creep-Feed Grinding process 
In spite of many advantages, the Creep Feed Grinding process is characterized by a lot of defects. Large depth of cut causes increasing of grinding forces and grinding power as well as great heat generation in the grinding zone [8, 11]. It increases the risk of occurrence of grinding burns [15]. The risk can be reduced by using high coolant flow rate with high pressure and specially designed nozzles [3]. Appropriate cooling conditions ensure reduction of the generated heat and easy removal of chips from the grinding zone. Creep-Feed Grinding also should be realizing with active grinding wheel cleaning process using high pressure coolant as a cleaning fluid [2, 6].

One of the most important component of the grinding process is the grinding wheel. The correct selection of the wheel specification can provide a finer surface quality and avoidance of thermal damages of the workpiece. In the Creep Feed Grinding process of Inconel alloys, the most commonly used types of abrasives are: White aluminum oxide, Pink aluminum oxide, Ruby aluminum oxide, Sintered aluminum oxide and Mixtures of white aluminum oxide with sintered aluminum oxide and white aluminum oxide with monocorundum. In specific cases even the Super abrasives are used. These wheels are also characterized by high porosity, which means open structure. This provides transportation of coolant to the cutting zone and evacuation of chips. Grinding wheels should have medium grains size from number 60 till 80. It depends on the required surface roughness. Grade and hardness of the grinding wheels should be soft or very soft [10].

Also technological parameters have a significant influence on the grinding process and the quality of the grinded surface. The most important parameters of the CFG process are the value of the grinding infeed, grinding feed and grinding speed [9]. The infeed and feed parameters have values characteristic for the deep grinding process. In the literature, the results of research on the impact of these parameters on the grinding process and the quality of the workpiece after grinding are available $[14,16]$. There are no available studies of the impact of grinding speed on the grinding process and the quality of the grinded surface. Therefore, experimental studies on the influence of grinding speed on the quality of the grinded surface of the Inconel 718 alloy have been carried out.

\section{EXPERIMENTAL SET-UP}

Experimental setup was built using $\mathrm{CNC}$ grinder Geibel\&Hotz FS 640 Z type. In the workspace a piezoelectric dynamometer with a special workpiece holder was mounted (fig. 2). In this holder the workpiece made of Inconel 718 was fixed.

Measurement of grinding force components was realized by using piezoelectric dynamometer Kistler 9121. A signal from the dynamometer was amplified by Charge amplifier Kistler 5070A. Afterwards the signal was converted to digital form using Analog/Digital converter. Force signal was filtered using a moving average. In the experimental researches two components of the grinding force were recorded: tangential and normal.

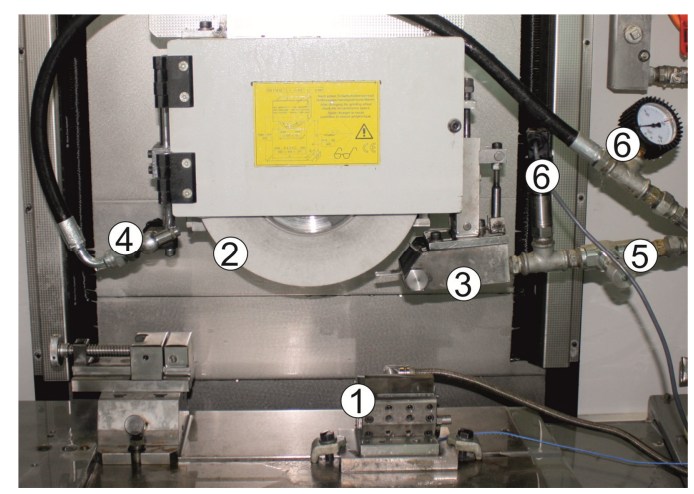

Fig. 2. The view of the set-up: 1) Workpiece holder, 2) Grinding wheel, 3) Coolant nozzle, 4) Cleaning nozzle, 5) Coolant valve, 6) Pressure sensors

After each test there was performed surface roughness measurement by the MarSurf M 300. Surface roughness measurement was performed at three points. At the beginning, in the middle and at the end of the sample. In this way, the change of surface roughness was determined in the grinding path corresponding to the grinding wheel wear.

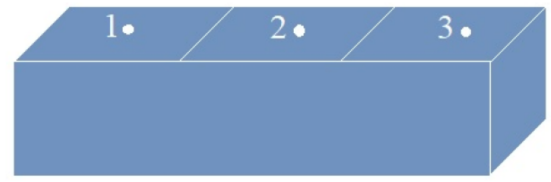

Fig. 3. The view of the measurement points

Grinding tests were conducted with the registration of grinding force components $F_{t}, F_{n}$ for the constants technological parameters shown in table 1 .

Tab. 1. Grinding conditions

\begin{tabular}{ll}
\hline Process & Concurrent Creep-Feeg Grinding \\
\hline $\begin{array}{l}\text { Grinding } \\
\text { machine }\end{array}$ & CNC grinder Geibel\&Hotz FS 640 Z type \\
\hline $\begin{array}{l}\text { Dressing } \\
\text { parameters }\end{array}$ & $\begin{array}{l}\text { Dresser: single grain diamond dresser } \\
v_{f d}=330 \mathrm{~mm} / \mathrm{min}, a_{e d}=0.02 \mathrm{~mm}\end{array}$ \\
\hline $\begin{array}{l}\text { Constant } \\
\text { grinding } \\
\text { parameters }\end{array}$ & $v_{f}=80 \mathrm{~mm} / \mathrm{min}, a_{e}=1 \mathrm{~mm}$, \\
\hline $\begin{array}{l}\text { Variables } \\
\text { grinding } \\
\text { parameters }\end{array}$ & $v_{s}=20 ; 22 ; 25 \mathrm{~m} / \mathrm{s}$ \\
\hline $\begin{array}{l}\text { Cooling } \\
\text { parameters }\end{array}$ & $\begin{array}{l}\text { Coolant: AquaTec } 7000 \\
p_{c}=80 \mathrm{~mm}\end{array}$ \\
\hline $\begin{array}{l}\text { Grinding } \\
\text { wheel }\end{array}$ & $\begin{array}{l}\text { White aluminum oxide }+ \text { Ruby corundum, } \\
\text { Structure } 15, \text { Grain } 70, \text { Grade G }\end{array}$ \\
\hline
\end{tabular}


During the experimental tests, the grinding speed was changing. It had values: $20,22,25 \mathrm{~m} / \mathrm{s}$. The rest of the grinding process parameters were constant.

\section{RESULTS AND DISCUSSION}

The following figures show the results of surface roughness measurements for different grinding speeds. The results are presented for three measuring points on the sample.

The diagrams show average values. Each measurement was repeated five times. In any case, the dispersion of measured values did not exceed $5 \%$.
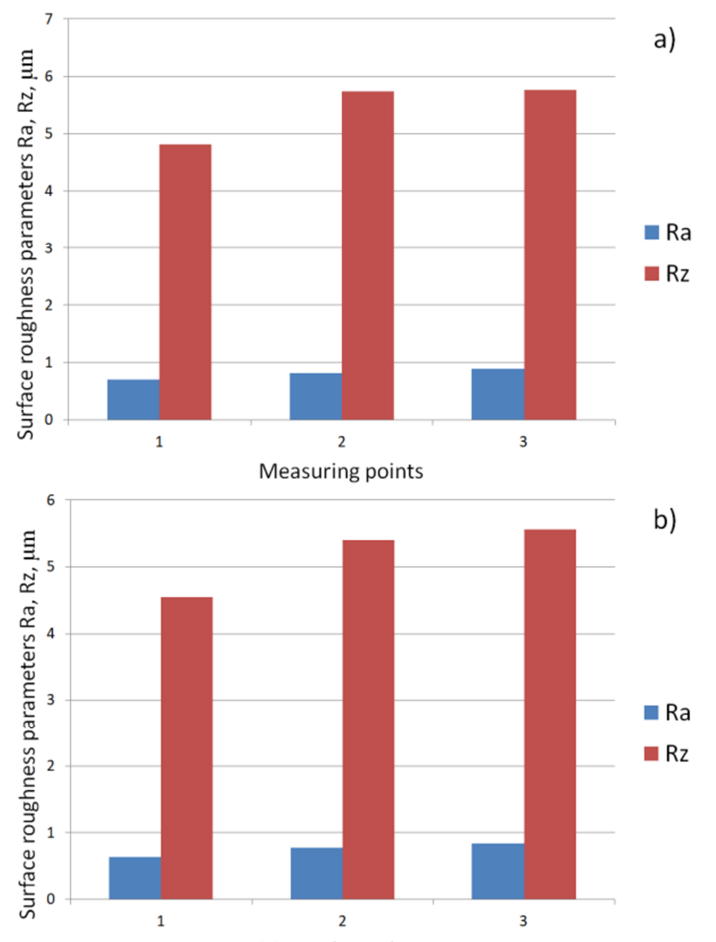

b)
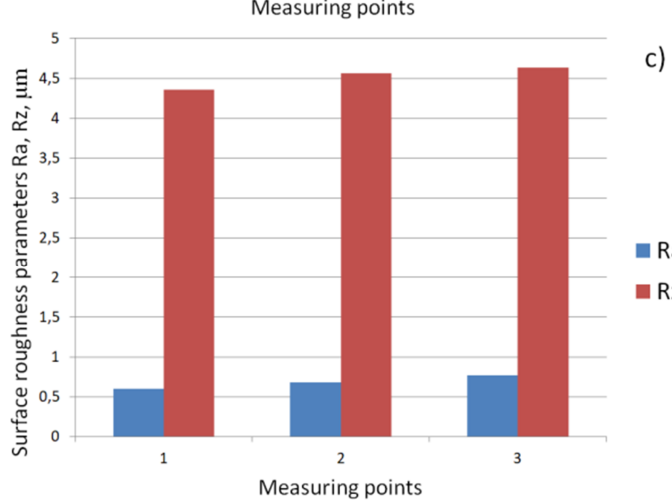

Fig. 4. Surface roughness for grinding speed: a) $20 \mathrm{~m} / \mathrm{s}$, b $22 \mathrm{~m} / \mathrm{s}, \mathrm{c}) 25 \mathrm{~m} / \mathrm{s}$

Presented research results show that the speed of grinding has a little effect on the roughness of the grinded surface. In the range of tested grinding speeds, the differences in roughness parameters were about
$15 \%$. However, it can be observed that for each experiment, along with the increase of the grinding speed, a reduction of the roughness parameters values was observed in each measuring point. In addition, it has been observed that a significant influence on the surface roughness has a progressive wear of the grinding wheel. Due to the fact that deep grinding is one-pass grinding, the wear of the grinding wheel is proportional to the grinding path. The presented research results show that the surface roughness changes by approx. 30\% in the grinding path of $l=50$ $\mathrm{mm}$. For example, for a grinding speed of $22 \mathrm{~m} / \mathrm{s}$, the roughness parameter $R a$ varies between 0.64 and 0.84 $\mu \mathrm{m}$. This means that the grinding wheel wear has a stronger effect on the roughness of the grinded surface than the grinding speed.

Taking the above into account, the analysis of changes in $R a$ and $R z$ roughness parameters was carried out. The function of average values of roughness parameters from the grinding speed was determined. There have been made attempts in order to match the equation of the straight line and the second degree polynomial (fig. 5). In both cases, the parameter $R^{2}=1$ was obtained. Therefore, a simpler forms of the equations, which are shown below, were adopted.

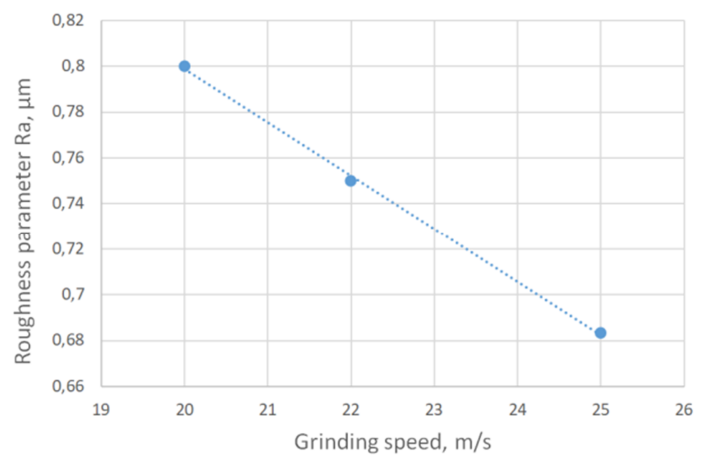

Fig. 5. The influence of grinding speed on the $R a$ parameter

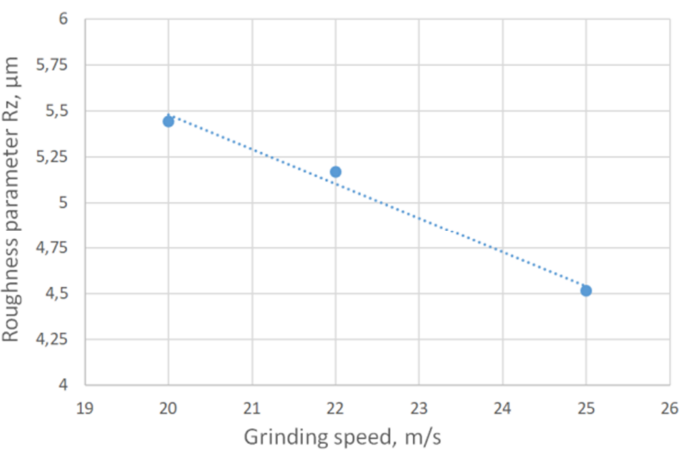

Fig. 6. The influence of grinding speed on the $R z$ parameter

The relationships between surface roughness parameters and grinding speed can be described by 
equations (1) for $R a$ parameter and (2) for $R z$ parameter:

$$
\begin{aligned}
& R a=-0.02 v_{s}+1.26, \\
& R z=-0.19 v_{s}+9.24 .
\end{aligned}
$$

The highest mean value of parameter $R a$ was obtained in the test with grinding speed $v_{s}=20 \mathrm{~m} / \mathrm{s}$ and is equal $R a=0.8 \mu \mathrm{m}$. As the grinding speed increases to a value of $v_{s}=22 \mathrm{~m} / \mathrm{s}$, the average value of the surface roughness parameter decreases to $R a=0.75 \mu \mathrm{m}$. For grinding speed $v_{s}=25 \mathrm{~m} / \mathrm{s}$, the lowest mean value of this parameter was $R a=0.68$ $\mu \mathrm{m}$.

The fig. 6 with changes of the average roughness parameter $R z$ in the function of grinding speed shows the same declining trend as the graph of the influence of the grinding speed on the parameter $R a$. The highest average value of the parameter $R z$ was obtained for grinding speed $v_{s}=20 \mathrm{~m} / \mathrm{s}$ and its value is $R z=5.44$ $\mu \mathrm{m}$. As the grinding speed increases to a value of $v_{s}=22 \mathrm{~m} / \mathrm{s}$, the average surface roughness parameter decreases to $R z=5.17 \mu \mathrm{m}$. For the grinding speed $v_{s}=25 \mathrm{~m} / \mathrm{s}$, the lowest value of $R z$ parameter was obtained. The decrease in the average roughness $R z$ parameter between grinding speed $v_{s}=20 \mathrm{~m} / \mathrm{s}$ and $v_{s}$ $=22 \mu \mathrm{m} / \mathrm{s}$ is $0.27 \mu \mathrm{m}$ and between $v_{s}=22 \mu \mathrm{m} / \mathrm{s}$ and $v_{s}=25 \mathrm{~m} / \mathrm{s}$ is $0.65 \mu \mathrm{m}$.

An analysis of the values of grinding force components was also carried out. The measurement of grinding force components was realized in order to obtain information on the grinding process. Fig. 7 shows an example of the distribution of the components of the grinding force in the time domain.

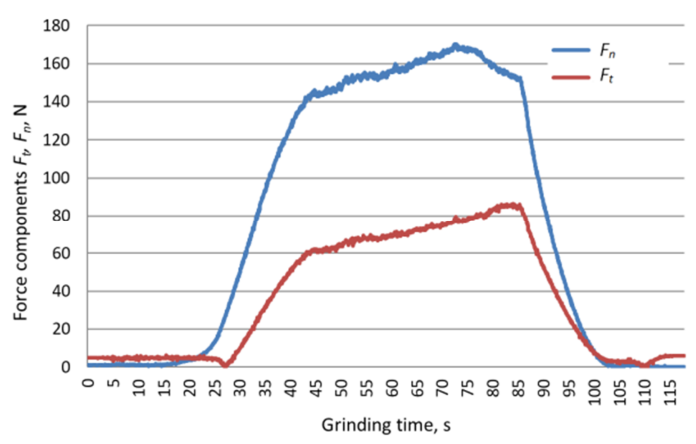

Fig. 7. Changes of the grinding force components in time domain

It can be observed that the normal component is about twice the tangent component. In addition, the value of the force components changes during grinding. It is clearly visible that the force value increases along with the grinding path and the progressive wear of the grinding wheel. It can be deduced from this that wheel wear has the greatest influence on the value of grinding force components.
In addition, it can be seen that at the beginning and in the end of grinding, the force components gently grow and decrease. This is due to the tension and stress relief of the machine tool-workpiece-grinding wheel system.

Then an analysis of the grinding force components for various grinding speed values was realized. The results are shown in fig. 8 and fig. 9. Both graphs show that the increase of the grinding speed causes a slight reduction of the grinding force components values. In the range of tested grinding speeds, grinding force changes around $10 \%$. Analyzing a normal force component, for a grinding speed of $v_{s}=20 \mathrm{~m} / \mathrm{s}$, its value was $F_{n}=129 \mathrm{~N}$. An increase in the grinding speed by $5 \mathrm{~m} / \mathrm{s}$ reduced the value of the normal component to $F_{n}=117 \mathrm{~N}$. This means a change of around $10 \%$. It can be seen that the change of normal force as a function of grinding speed has a linear function. The grinding speed also influence on the tangential component of the grinding force. For a grinding speed of $v_{s}=20 \mathrm{~m} / \mathrm{s}$, its value was $F_{t}=57 \mathrm{~N}$ An increase in grinding speed by $5 \mathrm{~m} / \mathrm{s}$ caused a reduction of the tangential component value to $F_{t}=49$ $\mathrm{N}$. This means a change of around $15 \%$. The change of the tangential force component as a function of the grinding speed is non-linear. It follows from the above that the grinding speed has a greater influence on the tangential component of the grinding force than on the normal component.

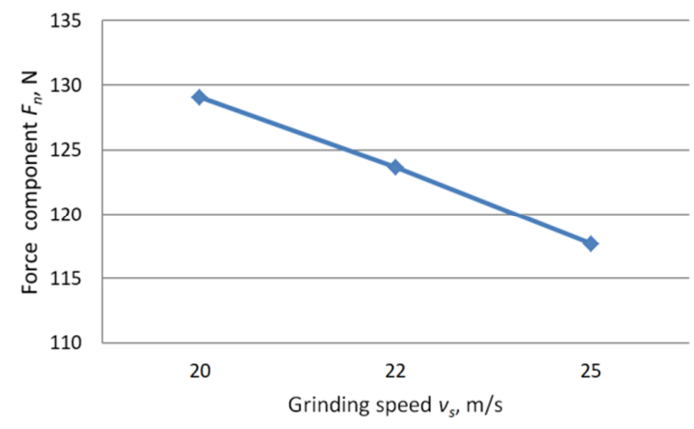

Fig. 8. The influence of grinding speed on the normal force component

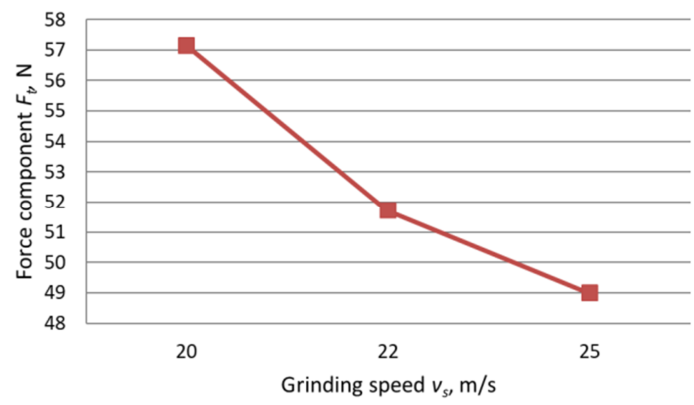

Fig. 9. The influence of grinding speed on the tangential force component 


\section{CONCLUSIONS}

There were realized experimental studies of the impact of grinding speed on the deep grinding process and the quality of the grinded surface. The variability of grinding speed was in the range which is usually used for grinding the Inconel 718 alloy. The tests were carried out using a concurrent grinding strategy with high coolant pressure and an active grinding wheel cleaning process.

Analyzing the obtained test results, it can be noticed that with the increase of the grinding speed, the value of roughness parameters $R a$ and $R z$ decreases. The lowest values of surface roughness parameters were obtained for grinding speed $v_{s}=25 \mathrm{~m} / \mathrm{s}$. For the grinding wheel made of a mixture of white and ruby aluminum oxide, values of $R a=0.6$ $\mu \mathrm{m}$ and $R z=4.36 \mu \mathrm{m}$ were obtained. It was observed that during grinding and progressive wear of the grinding wheel, the value of surface roughness parameters increased. This is mainly due to the wear of the grinding wheel. The obtained values of the surface roughness parameters $R a$ and $R z$ for the three tested grinding speeds have small differences.

The grinding speed also has an influence on the values of grinding force components. The tests show that the grinding speed has a stronger influence on the tangential component than the normal one. This can be explained by the fact that the tangential component is related to the main motion which is realizing by the grinding wheel. The change in the tangent component in the range of tested grinding speed values was $15 \%$. For the tangent and normal components of the grinding force, can be observed that the increase in the grinding speed always results in a lowering of the force value.

The research shows that the increase in grinding speed has a positive effect on the Inconel 718 CreepFeed Grinding process and the quality of the grinded surface. Increasing the grinding speed up to $v_{s}=25 \mathrm{~m} / \mathrm{s}$ resulted in lowering the grinding force components, which means less energy load of the grinded surface. In addition, after grinding at a speed of $v_{s}=25 \mathrm{~m} / \mathrm{s}$, much better surface quality was obtained. The roughness parameters have been reduced by approximately $30 \%$.

A further direction of Creep-Feed Grinding process analysis should be conducting experimental tests in a wider range of grinding speeds.

\section{Nomenclature}

$\begin{array}{ll}\text { Symbols } \\ a_{e} \quad-\text { grinding infeed, } \mathrm{mm} \\ a_{e d} \quad-\text { dressing infeed, } \mathrm{mm} \\ b_{w} \quad-\text { workpiece width, mm } \\ F_{t} \quad-\text { tangential force component, } \mathrm{N} \\ F_{n} \quad-\text { normal force component, } \mathrm{N} \\ i_{d} & - \text { number of dressing passes } \\ l_{w} & - \text { workpiece length, mm }\end{array}$

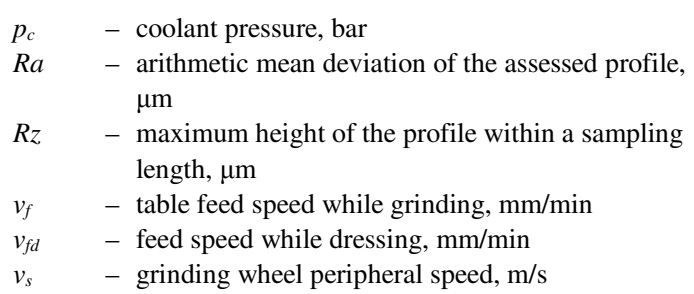

\section{References}

1. Bhaduri D., Soo S.L., Novovic D., Aspinwall D.K., Harden P., Waterhouse C., Bohr S., Mathieson A.C., Lucas M. (2013). Ultrasonic Assisted Creep Feed Grinding of Inconel 718. Procedia CIRP, Vol. 6, pp. 615-620.

2. Cameron A., Bauer R., Warkentin A. (2010). An investigation of the effects of wheel-cleaning parameters in creep-feed grinding. International Journal of Machine Tools and Manufacture. Vol. 50, No. 1, pp. 126-130.

3. Çolak O. (2012). Investigation on Machining Performance of Inconel 718 under High Pressure Cooling Conditions. Journal of Mechanical Engineering, Vol. 58, No. 11, pp. 683-690.

4. Ezugwu E. O., Bonney J., Yamane Y. (2003). An overview of the machinability of aeroengine alloys. Journal of Materials Processing Technology, Vol. 134, No. 2, pp. 233-253.

5. Ezugwu E. O., Z. Wang M., Machado A. R. (1999). The machinability of nickel-based alloys: a review. Journal of Materials Processing Technology, Vol. 86, pp. 1-16.

6. Heinzel C., Antsupov G. (2012). Prevention of wheel clogging in creep feed grinding by efficient tool cleaning. CIRP Annals, Vol. 61, No. 1, pp. 323-326.

7. Klocke F., Soo S. L., Karpuschewski B., Webster J. A., Novovic D., Elfizy A., Axinte D. A., Tönissen S. (2015). Abrasive machining of advanced aerospace alloys and composites. CIRP Annals - Manufacturing Technology, Vol. 64, No. 2, pp. 581-604.

8. Maksoud T. M. A. (2005). Heat transfer model for creepfeed grinding. Journal of Materials Processing Technology, Vol. 168, No. 3, pp. 448-463.

9. Malkin S., Guo Ch. (2008). Grinding Technology. Theory and Applications of Machining with Abrasives, Industrial Press, New York, USA.

10. Marinescu I. D., Hitchiner M., Uhlmann E., Rowe W. B., Inasaki I. (2007). Handbook of Machining with Grinding Wheels, CRC Press, Boca Raton, FL.

11. Ortega N., Bravo H., Pombo I., Sánchez J.A., Vidal G. (2015). Thermal Analysis of Creep Feed Grinding. Procedia Engineering, Vol. 132, pp. 1061-1068.

12. Pei-Lum T. (1995). Study on the grinding of Inconel 718. Journal of Materials Processing technology, Vol. 55, pp. 421-426.

13. Sedighi M., Afshari D. (2010). Creep feed grinding optimization by an integrated GA-NN system, Journal of Intelligent Manufacturing, Vol. 21, No. 6, pp. 657-663.

14. Wenfeng Ding, Jiuhua Xu, Zhenzhen Chen, Honghua Su, Yucan Fu (2010). Grindability and Surface Integrity of Cast Nickel-based Superalloy in Creep Feed Grinding with Brazed CBN Abrasive Wheels. Chinese Journal of Aeronautics, Vol. 23, No. 4, pp. 501-510.

15. Xu X. P., Yu Y. Q., Xu H. J. (2002). Effect of Grinding Temperatures on the Surface Integrity of a Nickel-Based Alloy. Journal of Materials Processing Technology, Vol. 129, pp. 359-353.

16. Zheng Jian-xin, Xu Jia-wen (2006). Experimental Research on the Ground Surface Quality of Creep Feed Ultrasonic Grinding Ceramics (A12O3). Chinese Journal of Aeronautics, Vol. 19, No. 4, pp. 359-365. 


\section{Biographical notes}

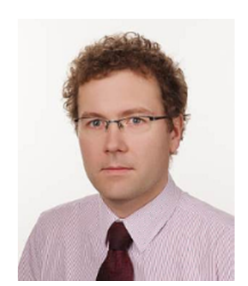

Łukasz Żyłka completed his Ph.D. in Mechanical Engineering in the field of diagnostics of the gear grinding process and is currently an Assistant Professor in the Department of Manufacturing Techniques and Automation at Rzeszow University of Technology, Poland. He has 15 years of teaching and research experience. His research interest include creep feed grinding, grinding of aerospace materials, high-pressure cooling in grinding processes, active grinding wheel cleaning process and also cooling nozzle construction. He has participated in 2 national research projects, presenting results of his work at 3 international and 10 national conferences, published more than 50 scientific papers in international and national journals. He is also the author of 5 national patents.

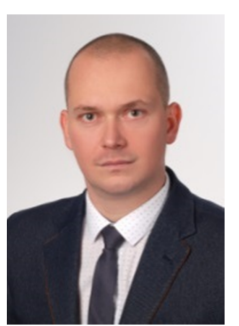

Marcin Płodzień completed his Ph.D. in Mechanical Engineering in the field of analysis of the high efficient milling process of aluminum alloys and is currently an Assistant Professor in the Department of Manufacturing Techniques and Automation at Rzeszow University of Technology, Poland. He has 10 years of teaching and research experience. His research interest include milling processes, cutting of aerospace materials, chip formation process, cryogenic cooling of cutting and numerical analysis of cutting tool construction.

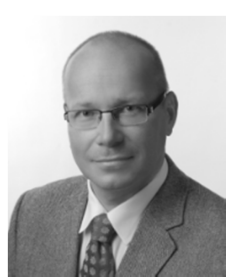

Robert Babiarz., completed his Ph.D. in Mechanical Engineering in the field of regulation of the cylindrical grinding process using RMS of acoustic emission signal and is currently an Assistant Professor in the Department of Manufacturing Techniques and Automation at Rzeszow University of Technology, Poland. His main scientific interest include diagnostic and adaptive regulation during machining of aerospace materials. Currently, he is conducting an experimental research focusing on grinding difficult-to-machine materials. 